\title{
Effects of an immunosuppressive treatment on the rat prostate
}

\author{
This article was published in the following Dove Press journal: \\ Drug Design, Development and Therapy \\ 12 September 2016 \\ Number of times this article has been viewed
}

\author{
Marta Grabowska' \\ Karolina Kędzierska² \\ Katarzyna Michałek ${ }^{3}$ \\ Sylwia Słuczanowska- \\ Głąbowska ${ }^{4}$ \\ Maciej Grabowski ${ }^{5}$ \\ Małgorzata Piasecka' \\ Andrzej Kram ${ }^{6}$ \\ Iwona Rotter ${ }^{7}$ \\ Aleksandra Rył' \\ Maria Laszczyńska' \\ 'Department of Histology and \\ Developmental Biology, Pomeranian \\ Medical University, ${ }^{2}$ Department of \\ Nephrology, Transplantology and \\ Internal Medicine, Pomeranian Medical \\ University, ${ }^{3}$ Department of Physiology, \\ Cytobiology and Proteomics, West \\ Pomeranian University of Technology, \\ ${ }^{4}$ Department of Physiology, \\ Pomeranian Medical University, \\ ${ }^{5}$ Department of Microbiology \\ and Applied Biotechnology, West \\ Pomeranian University of Technology, \\ ${ }^{6}$ Department of Pathology, West \\ Pomeranian Oncology Center, \\ ${ }^{7}$ Department of Medical \\ Rehabilitation, Pomeranian Medical \\ University, Szczecin, Poland
}

\footnotetext{
Correspondence: Marta Grabowska Department of Histology and

Developmental Biology, Pomeranian

Medical University, 48, Żołnierska Street,

7I-210 Szczecin, Poland

Tel +48 9| 4800908

Email martag@pum.edu.pl
}

\begin{abstract}
The aim of this study was to determine the influence of different combinations of immunosuppressive drugs on the morphology, ultrastructure, and expression of proliferating cell nuclear antigen and cytoskeleton proteins in the rat dorsolateral prostate. The studies were conducted on 48 male Wistar rats. The animals were divided into eight groups: a control group and seven experimental groups. For 6 months, the animals in the experimental groups were administered a combination of drugs including rapamycin (Rapa), cyclosporin A, tacrolimus (Tac), mycophenolate mofetil, and prednisone (Pred), according to the standard three-drug regimens for immunosuppressive therapy used in clinical practice. An evaluation of the morphology and ultrastructure was conducted, and a quantitative evaluation of the expression of proliferating cell nuclear antigen and desmin- and cytokeratin-positive cells with weak, moderate, and strong expression was performed. The combination of Rapa, Tac, and Pred caused the smallest morphological and ultrastructural changes in the rat prostate cells. In the case of rats whose treatment was switched to Rapa monotherapy, a decreased percentage of proliferating cells of both the glandular epithelium and the stroma was found. Decreases in body weight and changes in the expression of cytokeratin and desmin were observed in all the experimental rats. The combination of Rapa, Tac, and Pred would seem to be the most beneficial for patients who do not suffer from prostate diseases. Our results justify the use of inhibitors of the mammalian target of Rapa in the treatment of patients with prostate cancer. The changes in the expression of cytoskeleton proteins may be the result of direct adverse effects of the immunosuppressive drugs, which are studied in this article, on the structure and organization of intermediate filament proteins.
\end{abstract}

Keywords: rat prostate, ultrastructure, cytokeratin, desmin, PCNA, immunosuppressants

\section{Introduction}

Immunosuppressive drugs are used to improve the survival of a patient after organ transplantation by minimizing the reaction of the rejection of vascularized transplanted organs. ${ }^{1,2}$ The acute or chronic rejection of transplanted organs is a very complex process determined by several immunological and nonimmunological factors. ${ }^{3}$ Moreover, the choice of an appropriate immunosuppressive treatment protocol is of great importance. ${ }^{4-6}$ Consideration should be given to protocols with low levels of adverse effects, so that approaches would largely translate into the quality of life of patients.

Many substances with immunosuppressive properties can be used together in different combinations on account of their multidirectional effects. ${ }^{2}$ For this reason, in clinical practice, immunosuppressive therapy in humans is based on multidrug regimens. ${ }^{7,8}$ However, the bulk of the published studies focus on the impact of individual drugs on organs and tissues, despite the fact that these drugs may affect each other's metabolism. ${ }^{1,9-11}$ 
Various systemic side effects are known to be caused by immunosuppressive drugs. ${ }^{1,2,12}$ As a result of the use of such drugs, a considerable decrease in the number of rejected transplants is seen, but this is often proportional to the increased incidence of infections and malignancies. Moreover, studies have shown that renal transplant recipients are at risk of the early occurrence of prostate cancer. ${ }^{2,13,14}$

Proliferation processes are an important factor in maintaining normal graft function. Analogously, the appropriate structure of the glandular epithelium and the stroma of the prostate, as well as its function, depend on these processes. ${ }^{15}$ An important proliferation marker is proliferating cell nuclear antigen (PCNA). On the basis of expression studies of PCNA, this protein was determined to be a potential prognostic indicator that contributes to the development of predictive models for cancers and hyperplastic changes. ${ }^{16-19}$

Another factor that could be used to evaluate tissues in renal transplant recipients is the expression of intermediate filaments (IFs). Cytokeratin and desmin filaments play an important role in tissue regeneration and in proliferation processes. ${ }^{20-23}$ It has been shown that cytokeratins participate in the resistance of cells against apoptosis, which plays a key role during the response to inflammation. ${ }^{24,25}$ Research shows that desmin is a marker of late-stage differentiation of smooth muscles, and the changes in its expression are an important prognostic factor for recurrences of prostate cancer. ${ }^{26}$ The expression patterns of IFs can serve as valuable phenotypic markers in both normal and malignant tissues. Moreover, the knowledge concerning the differentiated expression of IFs (especially cytokeratins) found a practical application in the pathomorphological diagnostics of the prostate..$^{26-28}$ Expression disorders of cytoskeleton proteins caused by immunosuppressive drugs may contribute to the occurrence of pathological changes in transplanted organs and tissues. Studies addressing this problem may shed some light on the changes caused by these drugs on the cellular level.

One sign of good health among experimental animals is body weight gain..$^{29,30}$ The measurement of body weight is a simple but very effective way to assess the impact of treatment on important aspects such as appetite. It is worth mentioning that determination of body mass is important in the experimental model, which is proposed in this article, because immunosuppressive drugs have a narrow therapeutic window. Therefore, applied doses are calculated per unit of body weight to avoid the toxic effects of individual drugs associated with high doses.

There are many studies on the effects of immunosuppressants on the male reproductive system, especially on the testes, ${ }^{31-34}$ but very few articles have dealt with the prostate. ${ }^{35-37}$ Due to the absence of such information in the literature and given the increased risk of complications in transplant recipients, we have undertaken this research to determine the influence of different combinations of immunosuppressive drugs used in clinical practice on the morphology, ultrastructure, and expression of PCNA and cytoskeleton proteins in the rat dorsolateral prostate. It is worth mentioning that the results presented in this article are the continuation of our earlier studies. ${ }^{37}$

\section{Materials and methods}

\section{Animals}

The studies were conducted on 48 sexually mature 14-weekold male Wistar rats. The animals were obtained from a licensed breeding facility from the Institute of Occupational Medicine in Łódź, Poland. Prior to testing, all animals survived the 2-week adaptation period. Before starting the experiment, all animals were weighed, showing a mean weight of $305 \mathrm{~g}$. The animals were housed in cages (six rats per cage) with a 12-hour light/12-hour dark cycle and divided into eight groups: a control group (I) and seven experimental groups (II-VIII). The rats in group I received a placebo. For the period of 6 months, the animals in the experimental groups were administered drugs in their pharmaceutical oral form (in bread pellets) including: rapamycin (Rapa), cyclosporin A (CsA), tacrolimus (Tac), mycophenolate mofetil (MMF), and prednisone (Pred), according to the standard three-drug regimens of immunosuppressive therapy used most frequently in clinical practice. The drug doses administered were based on the literature..$^{9,10,38,39}$ The study scheme is presented in Table 1 .

\section{Local ethical commission statement}

The protocol for this study was in accordance with National Research Council guidelines for the care and use of laboratory animals, and approved by the Local Commission of Ethics for the Care and Use of Laboratory Animals in Szczecin, Poland (permit number 26/2011). The animals had health certificates issued by a veterinarian. Each step of the study protocol was designed in such a way as to minimize the pain and distress of animals.

\section{Collection of material for research}

A total of 46 rats completed the study (two rats in group III died in the fourth month of the experiment). After 6 months, the animals were anesthetized with ketamine hydrochloride $(50 \mathrm{mg} / \mathrm{kg})$ and their body weights were measured. During the section, the dorsolateral prostates were obtained. 
Table I Study scheme

\begin{tabular}{|c|c|c|c|c|}
\hline Group & $\begin{array}{l}\text { Number } \\
\text { of rats }\end{array}$ & Given drugs (pharmaceutical form) & $\begin{array}{l}\text { Dose }(\mathrm{mg} / \mathrm{kg} \text { of } \\
\text { body weight/day) }\end{array}$ & Feeding time \\
\hline 1 & 6 & - & - & - \\
\hline \multirow[t]{3}{*}{ II } & 6 & Rapa (Rapamune; Pfizer, Inc., New York, NY, USA) & 0.5 & 6 months \\
\hline & & Tac (Prograf; Astellas Pharma Inc., Tokyo, Japan) & 4 & \\
\hline & & Pred (Encorton; Polfa, Pabianice, Poland) & 4 & \\
\hline \multirow[t]{3}{*}{ III } & $6 / 4$ & Rapa (Rapamune) & 0.5 & 6 months \\
\hline & & $\begin{array}{l}\text { CsA (Sandimmum-Neoral; Novartis International AG, } \\
\text { Basel, Switzerland) }\end{array}$ & 5 & \\
\hline & & Pred (Encorton) & 4 & \\
\hline \multirow[t]{3}{*}{ IV } & 6 & Rapa (Rapamune) & 0.5 & 6 months \\
\hline & & MMF (CellCept; Hoffman-La Roche Ltd., Basel, Switzerland) & 20 & \\
\hline & & Pred (Encorton) & 4 & \\
\hline \multirow[t]{3}{*}{$\vee$} & 6 & CsA (Sandimmum-Neoral) & 5 & 6 months \\
\hline & & MMF (CellCept) & 20 & \\
\hline & & Pred (Encorton) & 4 & \\
\hline \multirow[t]{4}{*}{$\mathrm{VI}$} & 6 & CsA (Sandimmum-Neoral) & 5 & First 3 months \\
\hline & & MMF (CellCept) & 20 & \\
\hline & & Pred (Encorton) & 4 & \\
\hline & & Rapa (Rapamune) & 0.5 & Last 3 months \\
\hline \multirow[t]{3}{*}{ VII } & 6 & Tac (Prograf) & 4 & 6 months \\
\hline & & MMF (CellCept) & 20 & \\
\hline & & Pred (Encorton) & 4 & \\
\hline \multirow[t]{4}{*}{ VIII } & 6 & Tac (Prograf) & 4 & First 3 months \\
\hline & & MMF (CellCept) & 20 & \\
\hline & & Pred (Encorton) & 4 & \\
\hline & & Rapa (Rapamune) & 0.5 & Last 3 months \\
\hline
\end{tabular}

Notes: Drugs were given to rats in accordance with the regimens applied in clinical practice. I, control group; II-VIII, experimental groups. 6/4: Two rats died in the fourth month of the experiment.

Abbreviations: CsA, cyclosporin A; MMF, mycophenolate mofetil; Pred, prednisone; Rapa, rapamycin; Tac, tacrolimus.

We employed rat dorsolateral prostates in this research as they are homologous to the human prostate..$^{40,41}$

\section{Morphological and ultrastructural studies}

Dorsal lobes of the rat prostates of the control and experimental groups were routinely fixed in $4 \%$ buffered paraformaldehyde and embedded in paraffin. The paraffin blocks were sliced into $3 \mu \mathrm{m}$ sections. Next, the sections were stained using standard methods: hematoxylin and eosin, as well as periodic acid Schiff. ${ }^{42}$

To evaluate the ultrastructure in the transmission electron microscope, the lobes of the rat prostates were cut into pieces of volume of $\sim 1 \mathrm{~mm}^{3}$ and fixed in $2.5 \%$ glutaraldehyde solution (Sigma-Aldrich Co., St Louis, MO, USA) in $0.1 \mathrm{M}$ cacodylate buffer (Sigma-Aldrich Co.) at $\mathrm{pH} 7.4$ for 2 hours at $4^{\circ} \mathrm{C}$. The material was then fixed in a $1 \%$ solution of osmium tetroxide $\left(\mathrm{OsO}_{4}\right.$; Sigma-Aldrich Co.). The tissue was dehydrated in a series of ethanol and acetone $(100 \%)$ and gradually supersaturated with Spurr epoxy resin (Polysciences, Inc., Warrington, PA, USA). Subsequently, the material was immersed in capsules filled with epoxy resin. The blocks were cut into ultrathin scraps of 70-80 nm thick. The collected sections were counterstained sequentially with 9\% uranyl acetate (Sigma-Aldrich Co.) and 2.66\% lead citrate (Sigma-Aldrich Co.).

The histological preparations were examined under a light microscope (BX41; Olympus Corporation, Tokyo, Japan), while the ultrastructure was evaluated with a transmission electron microscope JEM-100CX (JEOL, Tokyo, Japan). The study was blinded, and one experienced pathologist and two histologists independently evaluated the ultrastructure and the histological preparations stained with hematoxylin and eosin.

\section{Immunohistochemistry}

For the immunohistochemical reactions, the following antibodies were used: monoclonal mouse antibody $\operatorname{IgG}$ against PCNA (clone PC10; Dako Denmark A/S, Glostrup, Denmark) diluted in the ratio of 1:200; monoclonal mouse antibody IgG against cytokeratin (clone MNF116; Dako Denmark A/S), which labels cytokeratins 5, 6, 8, 17, and probably 19 , diluted in the ratio of 1:50; and monoclonal mouse antibody IgG against desmin (clone D33; Dako Denmark A/S) diluted in the ratio of 1:50. 
The sections of the rat dorsolateral prostates were deparaffinized, hydrated, and boiled in target retrieval solution (Dako Denmark A/S) for 30 minutes at $\mathrm{pH} 6.0$ (for desmin) and pH 9.0 (for PCNA and cytokeratin) to restore the antigens. The activity of endogenous peroxidase was blocked by using peroxidase blocking solution (Dako Denmark A/S) for 10 minutes. The sections were incubated at room temperature with mouse monoclonal primary antibodies in a humid chamber for 30 minutes. Primary antibodies were diluted in diluent (Dako Denmark A/S). Afterward, the sections were incubated with a complex containing secondary antibody conjugated with horseradish peroxidase (Dako REAL EnVision Detection System Peroxidase/diaminobenzidine+, rabbit/mouse; Dako Denmark A/S). After washing out the secondary antibody, diaminobenzidine (Dako Denmark A/S) was applied. As the final step, the slides were counterstained with Mayer's hematoxylin, dehydrated, and coverslipped. Each step of the procedure was preceded by washing the slides with phosphate-buffered saline. All reactions were performed simultaneously under the same conditions. The slides were examined under a light microscope (BX 41).

\section{Quantitative computer image analysis of immunohistochemistry}

First, all the preparations were subjected to a scanning procedure (200× magnification, $0.25 \mu \mathrm{m}$ resolution) with a ScanScope AT2 scanner (Leica Microsystems, Wetzlar, Germany). Next, the digital images of the slides thus obtained were analyzed on a computer screen using an ImageScope viewer (Version 11.2.0.780; Aperio Technologies, Inc., Vista, CA, USA). For the automatic computer analysis of the nuclear immunohistochemical PCNA reaction, nuclear v9 algorithm (Version 11.2.0.780; Aperio Technologies, Inc.) was used, whereas for cytoplasmic immunohistochemical reactions of cytokeratin and desmin, cytoplasmic v2 algorithm (Version 11.2.0.780; Aperio Technologies, Inc.) was employed. Other parameters were set in such a way as to achieve compliance with the visual evaluation of color intensity, taking into account the threshold for a positive result, namely a brown color of the nucleus or cytoplasm of the cells. Using each algorithm, the percentage of PCNA-positive cells was determined quantitatively and the number of desminand cytokeratin-positive cells with weak, moderate, and strong expression was calculated quantitatively. For cells with PCNA expression, the limit of the intensity threshold of the positive nuclei was 162-210 units; for the negative nuclei, this was $<162$ units. For the cells with cytokeratin and desmin expression, the limit of the intensity threshold was 181-210 units for positive weak (+) cells, 151-180 units for positive moderate $(++)$ cells, 120-150 units for positive strong $(+++)$ cells, and $<120$ units for negative cells. To obtain reliable and repeatable values, the total number of PCNA-, desmin-, and cytokeratin-positive cells was counted in 60 random fields (ten fields in six slides for each group) with an average area of $0.32 \mathrm{~mm}^{2}$ (for PCNA in the glandular part), $0.14 \mathrm{~mm}^{2}$ (for PCNA in the stroma), $0.24 \mathrm{~mm}^{2}$ (for cytokeratin), and $0.08 \mathrm{~mm}^{2}$ (for desmin).

\section{Statistical analysis}

Statistical analysis was conducted using the Statistica 8.0 program for Windows (StatSoft, Krakow, Poland). For quantitative variables of PCNA-positive cells as well as for desmin- and cytokeratin-positive cells with weak, moderate, and strong expression in each group, the minimum and maximum values, arithmetic mean, and standard deviation were calculated. To assess the significance of the differences between the values obtained for each grade of the expression in each group, the Kruskal-Wallis test was performed. The variance analysis of Kruskal-Wallis was used due to the large deviation from the normal distribution. To assess the significance of the differences between the values obtained for PCNA-positive cells in the stroma and the glandular part in each group, a Mann-Whitney $U$-test was carried out. Differences were considered statistically significant when $P$-values were $<0.05$.

\section{Results}

An evaluation of the morphology and ultrastructure and the quantitative assessment of PCNA-positive cells were carried out in the glandular epithelium and stroma of rat dorsolateral prostates. Furthermore, a quantitative evaluation of desmin- and cytokeratin-positive cells with weak, moderate, and strong expression was conducted. The prostates of the animals from the experimental groups (II-VIII) and from the control group (I) were compared. Next, the groups in which the conversion of the treatment to Rapa took place were compared with the groups in which the treatment schemes did not include Rapa during the study.

\section{Body mass}

Lower body masses were found in all the treated groups II-VIII (Table 2). The rats in the control group had the highest body mass, whereas the animals in group II $(P<0.01)$, in which Rapa, Tac, and Pred were administered, had the lowest. Moreover, in group VI, in which the conversion of the treatment with CsA, MMF, and Pred on Rapa occurred, 
Table 2 Body mass of rats

\begin{tabular}{lllll}
\hline Group & Given drugs & \multicolumn{3}{l}{ Body mass $(\mathbf{g})$} \\
\cline { 3 - 5 } & & $\overline{\mathbf{x}} \pm$ SD & Me & Min-max \\
\hline I & - & $572.9 \pm 78 . I$ & 574 & $474-700$ \\
II & Rapa, Tac, Pred & $403.0 * \pm 54.3$ & 417 & $33 \mathrm{I}-480$ \\
III & Rapa, CsA, Pred & $467.0 \pm 54.9$ & 470 & $398-530$ \\
IV & Rapa, MMF, Pred & $435.7 \pm 58.3$ & $4 I 4$ & $385-546$ \\
V & CsA, MMF, Pred & $544.2 \pm 50.2$ & 554 & $48 \mathrm{I}-600$ \\
VI & CsA, MMF, Pred/Rapa & $428.8 \pm 53.9$ & 472.5 & $4 I I-563$ \\
VII & Tac, MMF, Pred & $482.5 \pm 66.7$ & 482.5 & $405-580$ \\
VIII & Tac, MMF, Pred/Rapa & $502.8 \pm 38.5$ & 494.5 & $465-569$ \\
\hline
\end{tabular}

Notes: I, control group; II-VIII, experimental groups. $* P<0.05$.

Abbreviations: $\mathrm{Cs} A$, cyclosporin A; Me, median; Min-max, minimum-maximum values; MMF, mycophenolate mofetil; Rapa, rapamycin; Pred, prednisone; Tac, tacrolimus; $\bar{x} \pm \mathrm{SD}$, mean \pm standard deviation.

lower body mass was noted than in group $\mathrm{V}$, in which CsA, MMF, and Pred were administered throughout the experiment. Moreover, in group VIII (in which the conversion of the treatment with Tac, MMF, and Pred on Rapa occurred), greater body mass was observed than in group VII, in which Tac, MMF, and Pred were administered throughout the experiment.

\section{Morphology and ultrastructure}

In the glandular part of the rat dorsolateral prostate, the secretory and lead-out sections were lined with single-layer cubical or cylindrical epithelium. Periodic-acid-Schiffpositive eosinophilic secretion was observed in the lumen of the acini. In all the studied groups (II-VIII), changes were observed in the glandular epithelium, mainly in the apical and perinuclear part of the cell. Furthermore, two types of cells were observed - with electron light and dark cytoplasm. Microvilli were seen on the cell surfaces.

\section{Group I: control}

In the control group, acini in the rat dorsolateral prostate were lined with cubical or cylindrical epithelium (Figure 1A), in which no significant changes were observed. Proper cisterns of the rough endoplasmic reticulum in the perinuclear region (Figure 2A) and proper Golgi cisterns located in the apical part of the cells were observed. In many cells, different types of acini with transported secretion were present, which took on different forms (condensed, fluffy, and star shaped). In addition, in the perinuclear part of the cells, normal narrow parallel cisterns of rough endoplasmic reticulum were observed.

\section{Group II: Rapa, Tac, and Pred}

In this group, the smallest changes were observed in the glandular epithelium, compared to other treatment groups.
The glandular epithelium was characterized by small infoldings into the lumen of the acini. During the analysis of the ultrastructure, the epithelium showed the features of atrophy in a small area.

\section{Group III: Rapa, CsA, and Pred}

In the acini, numerous infoldings of the glandular epithelium into the lumen of the acini were observed (Figure 1B). Moreover, in most of the cells, bloated cisterns were seen in the Golgi apparatus and in the rough endoplasmic reticulum (Figure $2 \mathrm{~B}$ ).

\section{Group IV: Rapa, MMF, and Pred}

Similar to group III, multiple infoldings of the glandular epithelium into the lumen of the acini were observed in the rat dorsolateral prostates of group IV. In the lumen of some acini, inflammatory cells were also seen (Figure 1C). Bloated dictyosomes of Golgi apparatus and rough endoplasmic reticulum (RER) cisterns were also noticed. Moreover, some cells were characterized by disorder in the organization of organelles and by shrunken nucleus.

\section{Group V: CsA, MMF, and Pred}

Highly atrophic epithelium was observed in many acini (Figure 1D). In several acini, hyperplasia of the glandular epithelium was also found. The presence of bloated Golgi apparatus cisterns in the apical part of the cells and of rough endoplasmic reticulum in the perinuclear region was noted. Condensed secretion was rarely observed in the secretory acini. On a large surface, the epithelium showed the features of atrophy with clear movement of the secretion apparatus (Figure 2C).

\section{Group VI: CsA, MMF, and Pred/Rapa}

Many infoldings of the glandular epithelium into the lumen of acini were found. The epithelium did not show any characteristics of atrophy. In addition, numerous inflammatory cells in the lumen of the acini were observed, along with a disorder in the normal structure of the glandular epithelium (Figure 1E). These changes were accompanied by the foci of the hyperplasia of epithelial cells. Very large bloated cisterns of Golgi apparatus and rough endoplasmic reticulum were also noted. In this group, more severe morphological changes were observed than in group $\mathrm{V}$.

\section{Group VII:Tac, MMF, and Pred}

As in the case of group VI, numerous disorders of the normal structure of the epithelium, and focal hyperplasia of the 

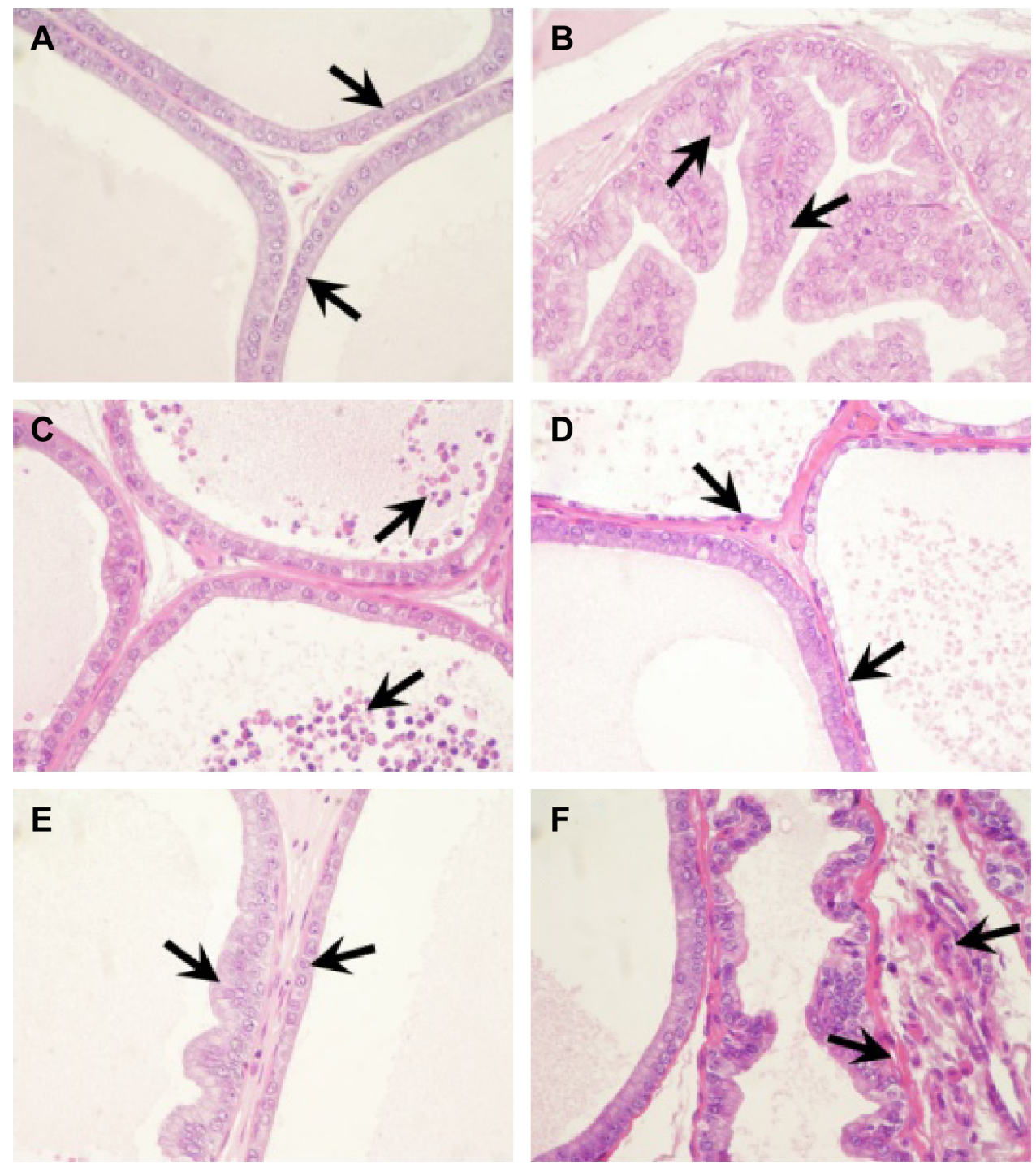

Figure I Morphology of the rat dorsolateral prostate.

Notes: (A) Epithelial cells (arrows) of the control group (I). (B) Numerous papillary infoldings of the glandular epithelium protruding into the acini lumen (arrows), hyperplastic epithelium, group III. (C) Inflammatory cells in the lumen of some acini (arrows), group IV. (D) Distinctly atrophic epithelium (arrows), group V. (E) Disorder of the normal structure of the epithelium (arrows), cells of different height, focal hyperplasia, group VI. (F) Edema (arrows) in the walls of acini in the stroma, group VIII. H\&E staining, magnification $\times 600$. I: control group; III, IV, V, VI and VIII: experimental groups.

Abbreviation: H\&E, hematoxylin and eosin.

glandular epithelium, were observed, though the changes were clearly smaller. Bloated RER was also seen in the perinuclear region of the cells. The Golgi apparatus was also characterized by bloated cisterns, and condensed secretion was present in the secretory acini.

\section{Group VIII:Tac, MMF, and Pred/Rapa}

Focal hyperplasia of the glandular epithelium and infoldings of the epithelium into the lumen of the acini were observed. Moreover, in comparison to group VII, the changes identified in this group were clearly greater. In some areas, the epithelium showed features of atrophy. In addition, in the stroma, edema was observed within the walls of the acini (Figure 1F).
As in the case of group VI, very large bloated cisterns of the secretion apparatus were found (Figure 2D).

\section{Immunohistochemistry PCNA}

In the rat dorsolateral prostate, PCNA-positive cells were characterized by brown-stained nuclei (Figure $3 \mathrm{~A}$ and B), in both the glandular epithelium and the stroma. The percentage of PCNA-positive cells in the control and experimental groups, in the glandular and stromal part, is presented in Table S1 and Figure 4.

The percentage values obtained for PCNA-positive cells in the glandular epithelium of the control group differed 

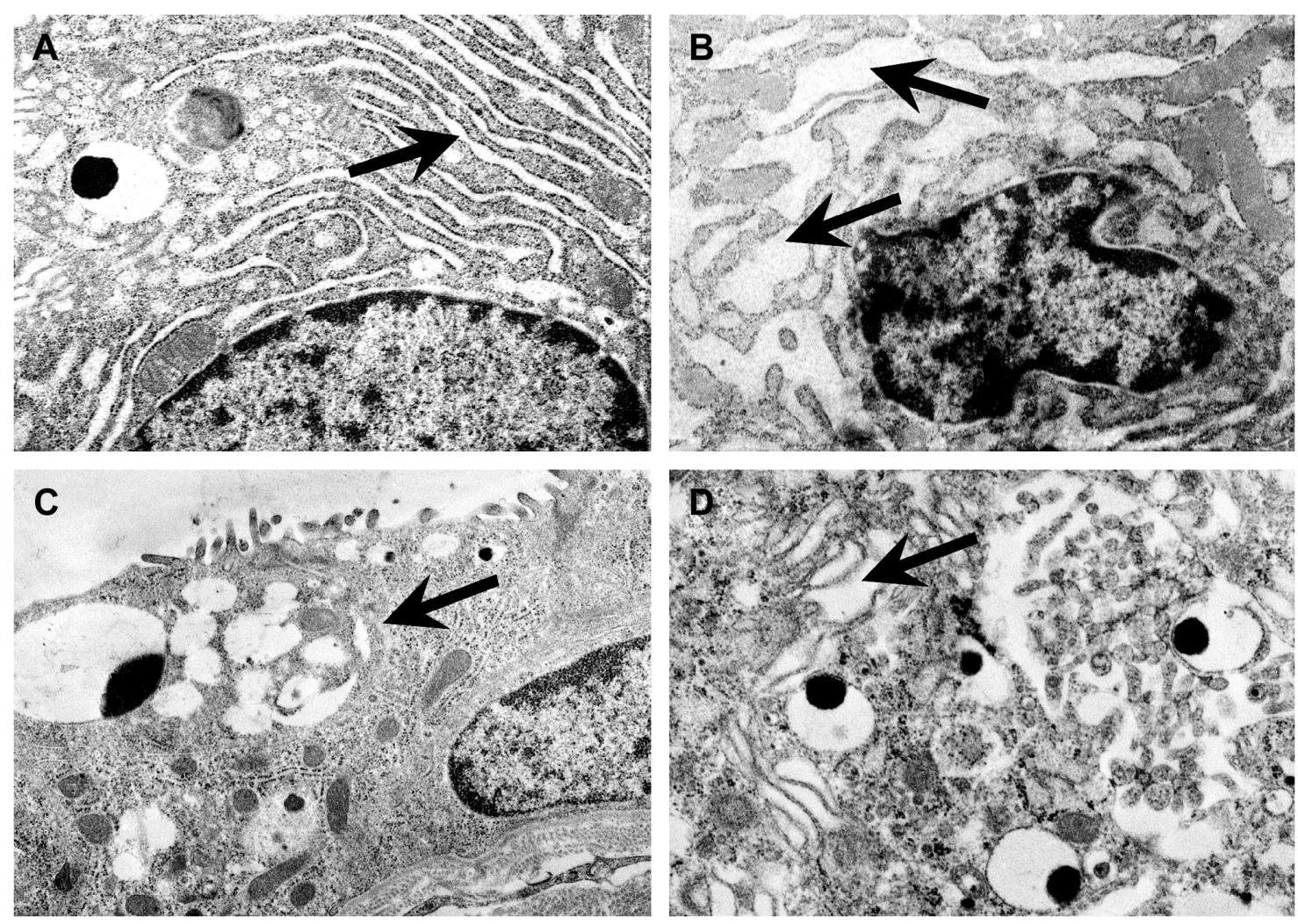

Figure 2 Ultrastructure of the rat dorsolateral prostate.

Notes: (A) Proper cisterns of the rough endoplasmic reticulum in the perinuclear region (arrow) of the control group (I), $\times 10,200$. (B) Bloated cisterns of the rough endoplasmic reticulum (arrows). Group III, $\times 10,200$. (C) Epithelium showing the features of atrophy with movement of the secretion apparatus from the supernuclear region to the side part of the cell (arrow), group V, $\times 6,600$. (D) Bloated cisterns of the Golgi apparatus (arrow), group VIII, ×6,600. I: control group; III, V and VIII: experimental groups.

statistically significantly from those of groups III, IV, VI, and VIII $(P<0.001)$. The highest percentage of PCNA-positive cells in the glandular epithelium was noted in group IV, in which Rapa, MMF, and Pred were administered. The lowest percentage of PCNA-positive cells in the epithelium was observed in group VI, in which CsA, MMF, and Pred were administered in the first 3 months, but only Rapa in the next 3 months. The percentage values obtained for PCNA-positive cells in the stroma of the control group differed statistically significantly from those of groups III and VIII ( $P=0.034$ and $P<0.001$, respectively). The highest percentage of PCNApositive cells in the stroma was found in group III $(P=0.034)$, in which Rapa, CsA, and Pred were administered. The lowest percentage of PCNA-positive cells in the stroma was noted in group VIII $(P<0.001)$, in which Tac, MMF, and Pred were administered during the first 3 months and only Rapa in the next 3 months. The percentages of PCNA-positive cells in the glandular epithelium of all groups, apart from group VI, in comparison to the values for the stroma in particular groups, demonstrated statistically significant differences $(P<0.001)$. The percentage values obtained in group VI (in which CsA, MMF, and Pred were administered during the first 3 months and Rapa alone in the remaining period) were significantly lower than in group $\mathrm{V}$, in which throughout the experiment CsA, MMF, and Pred were administered. The situation was similar when groups VII and VIII were compared. In group VIII (in which Tac, MMF, and Pred were administered for the first 3 months and Rapa alone during the next 3 months), the percentage of PCNA-positive cells was significantly lower than in group VII, in which Tac, MMF, and Pred were administered throughout the experiment.

\section{Cytokeratin}

Cytokeratin-positive cells were found in the glandular epithelium and vascular endothelium of the stroma of the rat prostate. These cells were characterized by brown-stained cytoplasm (Figure 3C and D). The percentages of cytokeratinpositive cells with weak, moderate, and strong expression in individual groups (I-VIII) are presented in Table S2 and Figure 5. The percentage of cytokeratin-positive cells with weak, moderate, and strong expression in group I differed statistically from all the other groups: II, III, IV, V, VI, VII, and VIII ( $P=0.001$ and $P<0.001$, respectively). The highest percentage of cytokeratin-positive cells with weak expression 

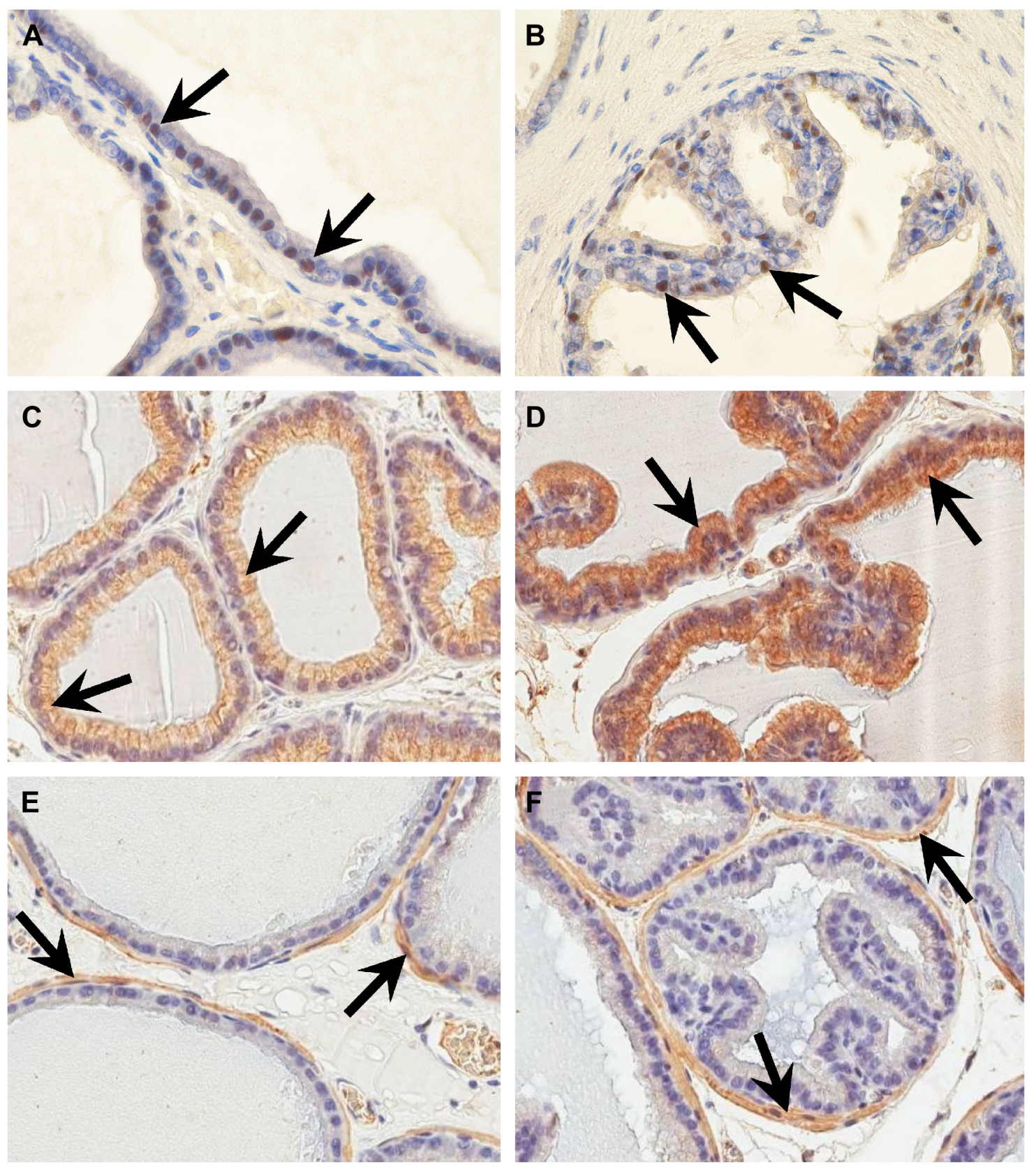

Figure 3 Immunolocalization and immunoexpression of PCNA (A, B), cytokeratin (C, D), and desmin (E, F) in the rat dorsolateral prostate.

Notes: (A, B) PCNA-positive cells of the glandular epithelium (arrows). (A) Control group (I), (B) group III. (C, D) Cytokeratin-positive cells of the glandular epithelium (arrows). (C) Control group (I), (D) group VII. (E, F) Desmin-positive cells of the smooth myocytes around acini (arrows). (E) Control group (I), (F) group VII. Magnification $\times 600$. I: control group; III and VII: experimental groups.

Abbreviation: PCNA, proliferating cell nuclear antigen.

was found in the control group (I), as well as in group II ( $P=0.001$ vs control), in which Rapa, Tac, and Pred were administered. The lowest percentage of cytokeratin-positive cells with weak expression was found in group VII $(P<0.001$ vs control), in which Tac, MMF, and Pred were administered. The highest percentage of cytokeratin-positive cells with moderate expression was found in group IV $(P<0.001$ vs control), in which Rapa, MMF, and Pred were administered, and in group $\mathrm{V}(P<0.001$ vs control), in which CsA, MMF, and Pred were administered. The lowest percentage of cytokeratin-positive cells with moderate expression was found in the control group, as well as in group VIII $(P<0.001$ vs control), in which Tac, MMF, and Pred were administered in the first 3 months and Rapa alone in the following 3 months. The highest percentage of cytokeratinpositive cells with strong expression was found in group VII $(P<0.001$ vs control), in which Tac, MMF, and Pred were administered. The lowest percentage of cytokeratin-positive cells with strong expression was found in the control group, as well as in group II ( $P<0.001$ vs control), in which Rapa, 


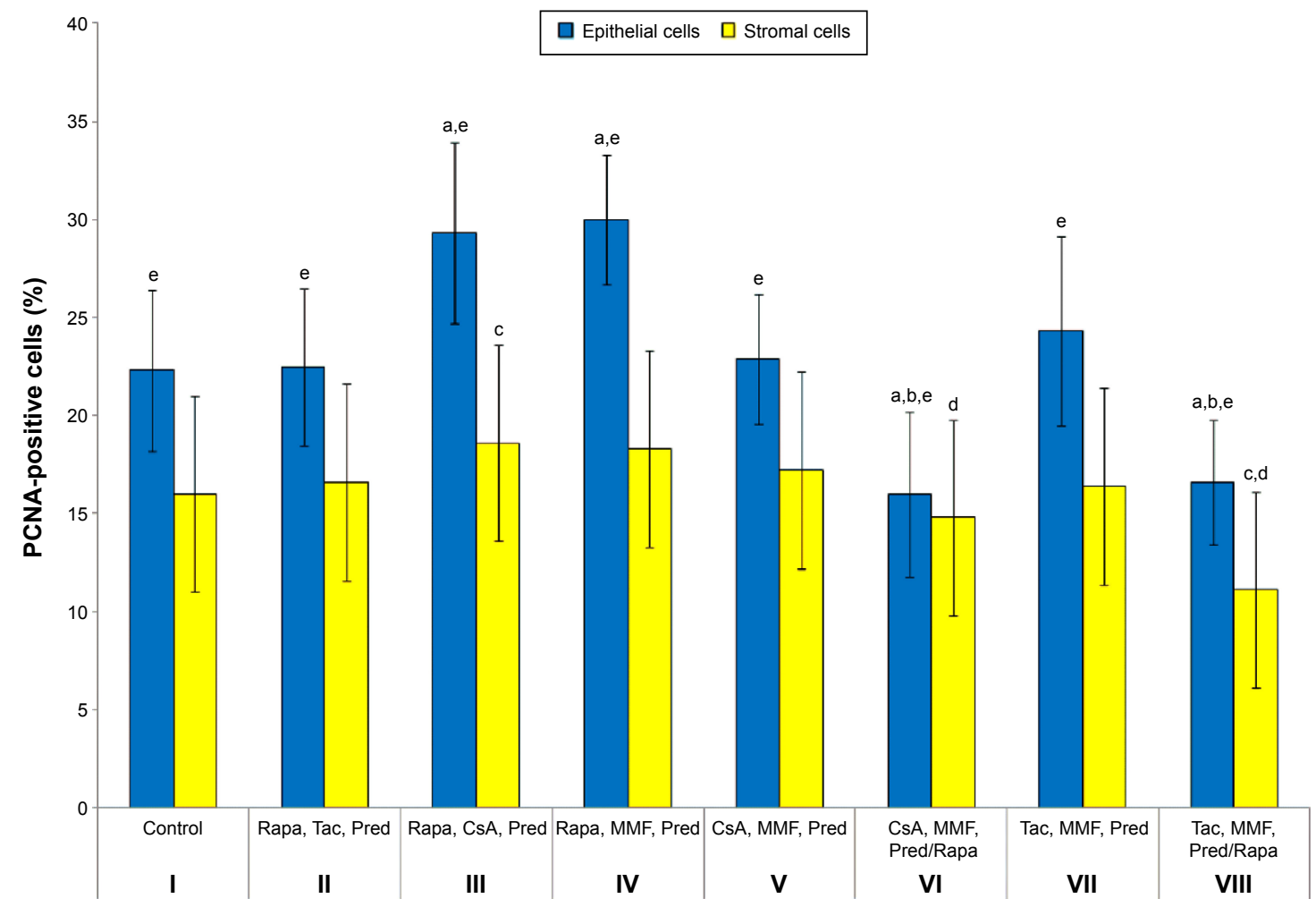

Figure 4 Percentage of PCNA-positive cells in epithelium and stroma in the rat dorsolateral prostate in control (I) and experimental groups (II-VIII).

Notes: a, significantly different vs the controls in epithelial cells; b, groups with the conversion of the treatment to Rapa, significantly different vs the groups without Rapa in epithelial cells (VI vs V and VIII vs VII); c, significantly different vs controls in stromal cells; d, groups with the conversion of the treatment to Rapa, significantly different vs the groups without Rapa in stromal cells (VI vs V and VIII vs VII); e, PCNA-positive epithelial cells, significantly different vs PCNA-positive stromal cells.

Abbreviations: CsA, cyclosporin A; MMF, mycophenolate mofetil; Rapa, rapamycin; PCNA, proliferating cell nuclear antigen; Pred, prednisone; Tac, tacrolimus.

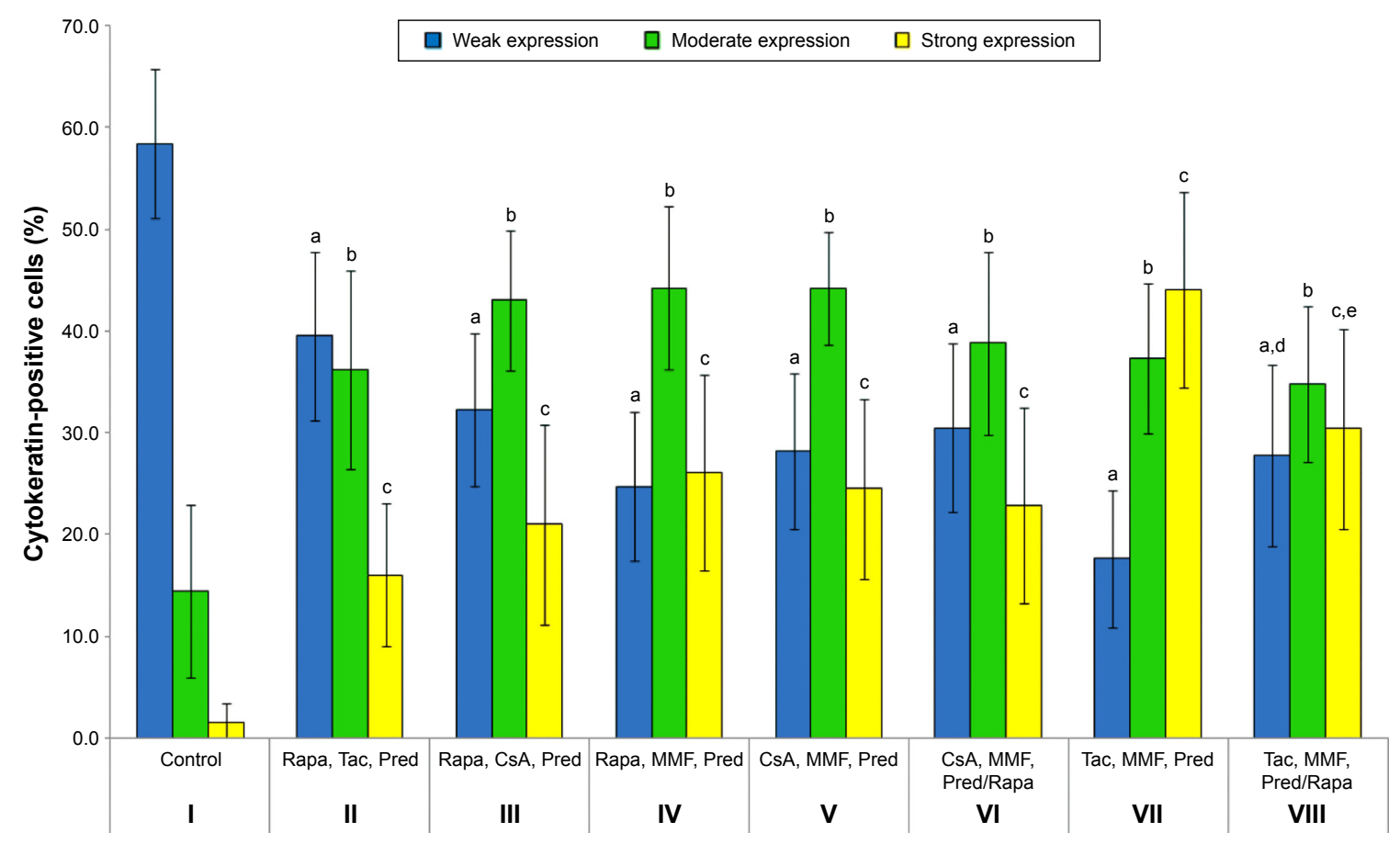

Figure 5 Percentage of cytokeratin-positive cells in epithelium in the rat dorsolateral prostate in control (I) and experimental groups (II-VIII).

Notes: a, significantly different vs the controls for the cells with weak expression; b, significantly different vs the controls for the cells with moderate expression; c, significantly different vs the controls for the cells with strong expression; d, groups with the conversion of the treatment to Rapa, significantly different vs the groups without Rapa (VI vs V and VIII vs VII) for the cells with weak expression; e, groups with the conversion of the treatment to Rapa, significantly different vs the groups without Rapa (VI vs V and VIII vs VII) for the cells with strong expression.

Abbreviations: CsA, cyclosporin A; MMF, mycophenolate mofetil; Rapa, rapamycin; Pred, prednisone; Tac, tacrolimus. 
Tac, and Pred were administered. In group VI (in which CsA, MMF, and Pred were administered in the first 3 months and Rapa along during the remaining period), the percentage of the cells showing moderate and strong expression of cytokeratin was lower (statistically insignificant) than in group $\mathrm{V}$ (in which CsA, MMF, and Pred were administered during the whole duration of the experiment). The comparison of groups VII and VIII gave similar outcomes.

\section{Desmin}

Desmin-positive cells were localized in the stroma. The expression of desmin was observed in the smooth myocytes around the acini and in the smooth myocytes of the vascular walls; they were characterized by brown-stained cytoplasm (Figure 3E and F). The percentage of desmin-positive cells with weak, moderate, and strong expression in each of the groups (I-VIII) is presented in Table S3 and Figure 6.

The percentage of desmin-positive cells with weak expression of group I differed statistically significantly from that of groups II, V, VII, and VIII $(P<0.001)$. The highest percentage of desmin-positive cells with weak expression was found in group IV (statistically insignificant vs control), in which Rapa, MMF, and Pred were administered, and in group VI (statistically insignificant vs control), in which CsA,
MMF, and Pred were administered in the first 3 months and Rapa alone in the following 3 months. The lowest percentage of desmin-positive cells with weak expression was found in group II ( $P<0.001$ vs control $)$, in which Rapa, Tac, and Pred were administered. The percentage of desmin-positive cells with moderate expression for group I differed statistically significantly from that for groups III, IV, V, VII, and VIII ( $P<0.001$ and $P=0.025$, respectively). The highest percentage of desmin-positive cells with moderate expression was found in group VII $(P<0.001$ vs control), in which Tac, MMF, and Pred were administered. The lowest percentage of desmin-positive cells with moderate expression was found in group IV ( $P<0.001$ vs control), in which Rapa, MMF, and Pred were administered. The percentage of desmin-positive cells with strong expression for group I differed statistically significantly from that for groups II, IV, V, VII, and VIII ( $P<0.001$ and $P=0.002$, respectively). The highest percentage of desmin-positive cells with strong expression was found in group II ( $P<0.001$ vs control), in which Rapa, Tac, and Pred were administered. The lowest percentage of desminpositive cells with strong expression was found in group IV $(P=0.002$ vs control), in which Rapa, MMF, and Pred were administered. In group VI (in which CsA, MMF, and Pred were administered in the first 3 months and Rapa alone during

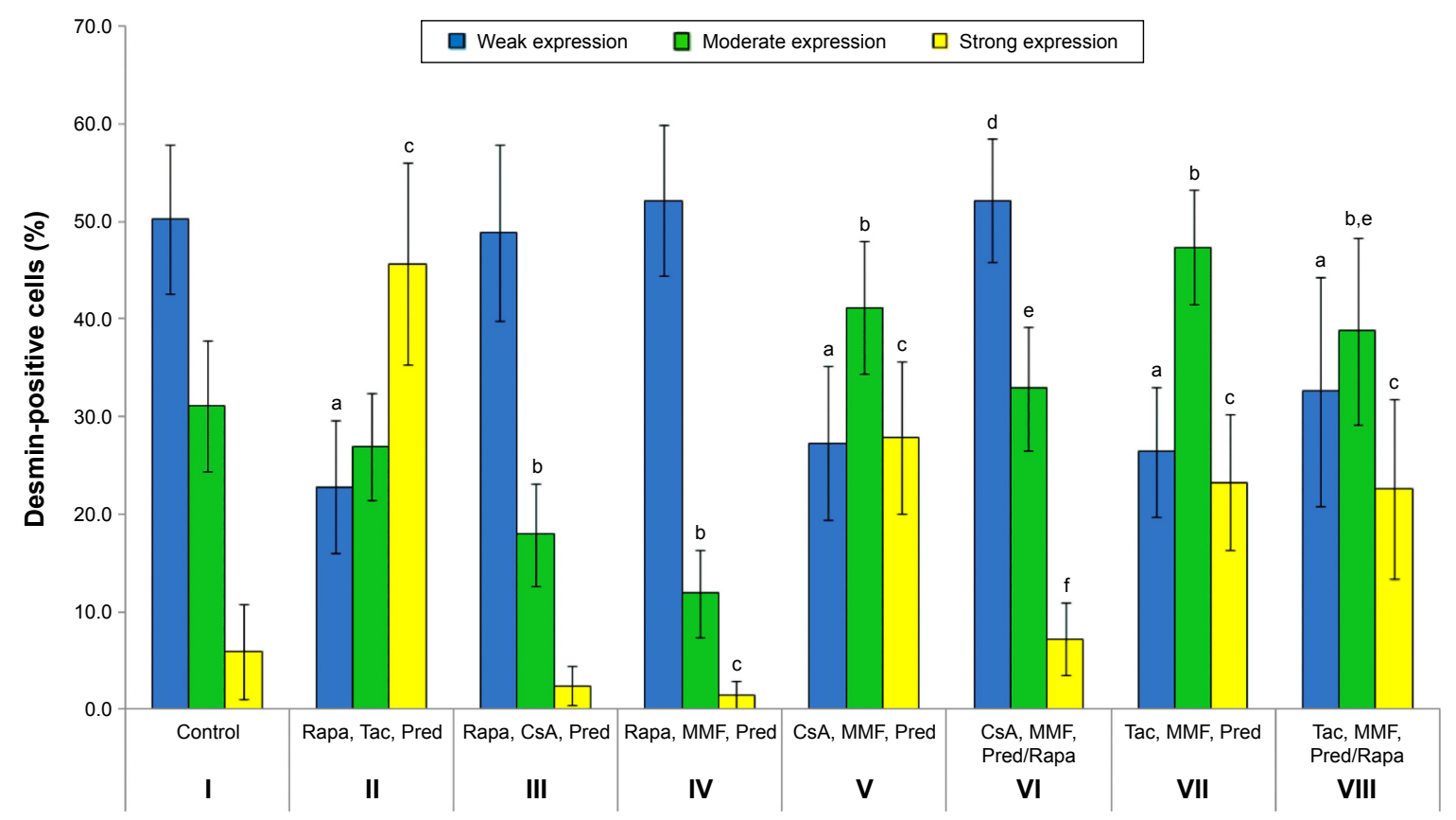

Figure 6 Percentage of desmin-positive cells in epithelium in the rat dorsolateral prostate in control (I) and experimental groups (II-VIII).

Notes: a, significantly different vs the controls for the cells with weak expression; b, significantly different vs the controls for the cells with moderate expression; c, significantly different vs the controls for the cells with strong expression; d, groups with the conversion of the treatment to Rapa, significantly different vs the groups without Rapa (VI vs V and VIII vs VII) for the cells with weak expression; e, groups with the conversion of the treatment to Rapa, significantly different vs the groups without Rapa (VI vs V and VIII vs VII) for the cells with moderate expression; f, groups with the conversion of the treatment to Rapa, significantly different vs the groups without Rapa (VI vs $V$ and VIII vs VII) for the cells with strong expression.

Abbreviations: CsA, cyclosporin A; MMF, mycophenolate mofetil; Rapa, rapamycin; Pred, prednisone; Tac, tacrolimus. 
the remaining period) the percentage of the cells showing moderate and strong expression of desmin was significantly lower than in group V (in which CsA, MMF, and Pred were administered throughout the experiment). Comparison of groups VII and VIII gave similar results. In group VIII (in which Tac, MMF, and Pred were administered in the first 3 months and Rapa alone during the next 3 months), the percentage of the cells showing moderate and strong desmin expression was significantly lower in comparison to group VII (in which Tac, MMF, and Pred were administered during the whole duration of the experiment).

\section{Discussion}

In the available literature, there are few publications on the effects of different combinations of immunosuppressive drugs on the prostate. Only our earlier studies relate to the effects of various combinations of immunosuppressants on the morphology and the expression of PCNA and cytokeratin in the prostate. ${ }^{37,43}$ So far, no research has been found concerning the impact of the standard three-drug combinations of immunosuppressive drugs on the ultrastructure and the expression of desmin in the prostate. Moreover, a quantitative evaluation, with the division of the prostate into glandular and stromal parts, was performed. Our study can thus be regarded as innovative.

In the experiment conducted, it was attempted to develop a model of the action of the various immunosuppressive drugs that might be comparable to long-term immunosuppressive therapy in humans following organ transplantation. The experiment was conducted for 6 months owing to the fact that the rat's average life span varies from 2 years to 3 years, which reflects $\sim 12-15$ years of a human life. ${ }^{44,45}$ As a result, the presented findings relate to the long-term effects of the particular combinations of immunosuppressive drugs. To compare, in many studies on the effects of immunosuppressive drugs on various organs, the time of the drug administration was relatively short. ${ }^{10,32,35,46}$ The fact that a physiological enteral route of the drug administration was chosen, rather than an intraperitoneal or intravenous route, as in some research on animal models, speaks to the advantage of the presented experimental model. ${ }^{47-49}$

In this experiment, a loss of body weight was observed in all the experimental rats. The highest (statistically significant) decrease in body mass was found in the animals in group II, in which Rapa, Tac, and Pred were administered. Other researchers have also observed a weight loss in both animals and humans undergoing immunosuppressive therapy. ${ }^{31,35,47,50-52}$ The effect of particular immunosuppressive drugs on the body mass was also examined. Rovira et $\mathrm{al}^{52}$ observed that rats receiving $\mathrm{Cs} A$ had higher body weight than animals on the CsA-free treatment scheme. In our experimental model, the positive effect exerted by CsA in CsA-based schemes on the weight of the rats was confirmed, while a considerable body weight loss was also found in rats treated with Rapa. Moreover, a decrease in the body weight was also found in the case of the conversion treatment from CsA-based regimens to Rapa. Other authors have also confirmed these observations. ${ }^{50}$ The weight loss caused by the administration of various combinations of immunosuppressive drugs may be related to their influence on cell growth processes and metabolism.

Both morphology and ultrastructure studies have shown that, in rat dorsolateral prostates in the group in which CsA, MMF, and Pred were administered, the epithelium was markedly atrophic. In our earlier studies conducted on the rat ventral prostate, a highly atrophied epithelium was observed in the group in which Rapa, CsA, and Pred were administered. ${ }^{37}$ This can be explained by the fact that the ventral lobe differs structurally and functionally from the dorsolateral unit. ${ }^{41}$ Unfortunately, other researchers have focused on identifying the impact of individual immunosuppressive drugs on the prostate. ${ }^{35,36}$ In our study, in all the groups, in which the atrophic epithelium was observed, calcineurin inhibitors (CsA or Tac) were administered. Some authors have observed that $\mathrm{CsA}$ causes a significant reduction in the absolute volume of all prostate components, including the epithelium in the ventral lobe of the rat prostate..$^{35,36}$ These authors observed that, as a result of the administration of CsA, the glandular epithelial cells were clearly lower. Moreover, the ultrastructural analysis confirmed the epithelial atrophy. The morphological changes observed in groups with the conversion of the treatment to Rapa were more severe than in groups in which animals did not receive Rapa. Literature data confirm that, in rats, the conversion of the treatment from CsA to Rapa ultimately leads to larger structural damages and testicle dysfunctions than does the continuation of treatment with $\mathrm{CsA} .^{50}$

In the glandular epithelium and stroma of the rat dorsolateral prostate, the lowest percentage of PCNA-positive cells was observed in groups with the conversion of the treatment to monotherapy with Rapa. Interestingly, these values were lower than in groups in which animals did not receive Rapa at all during the experiment. In our earlier studies on rat ventral prostates, the results had a similar distribution. ${ }^{37}$ Our results show that Rapa has antiproliferative activity. Other researchers have confirmed that Rapa exerts antiproliferative 
effects. ${ }^{38,46}$ In groups III and IV, in which rats received Rapa in combination with other drugs throughout the experiment, there were no fewer PCNA-positive cells than in the groups in which animals did not receive Rapa. The results were analogous in our earlier studies. In this experimental model, Rapa in combination with other drugs had less influence on the proliferation of cells in the dorsolateral lobe of the rat prostate. Unfortunately, we could not find any studies on the impact of immunosuppressive drugs on the expression of PCNA in the prostate. However, studies carried out on other models confirm the results obtained. Zhuang et $\mathrm{al}^{53}$ showed that the prolonged supply of Rapa inhibits the proliferation of PC-3 cells of prostate cancer. Other researchers ${ }^{54}$ have confirmed the antiproliferative properties of Rapa, observing that Rapa inhibits the proliferation of human keratinocyte stem cells by blocking the cell progression cycle in the G1 phase.

Cytokeratins constitute the most durable part of the cell cytoskeleton; for that reason, they are primarily responsible for protecting epithelial cells from mechanical tensions. They also play an important role in the regulation of cell growth. ${ }^{20,21}$ The expression of individual cytokeratins depends on the type of epithelium, the period of embryonic development, the level of cell differentiation, and the condition of the organism. ${ }^{55}$ Disturbances in the expression of cytokeratin may have a negative impact on processes in which regulation IFs are involved. In the dorsolateral lobe, in all the treatment groups (II-VIII), more cells exhibiting moderate and strong expression of cytokeratin were observed than in the control group. Unfortunately, we could not find any publications on the impact of even single immunosuppressant drugs on the organization of cytokeratin filaments in the prostate. The available literature indicates the negative impact of only certain immunosuppressive drugs on cytokeratins. Such studies have shown that CsA has a selectively toxic effect on cytokeratin filaments through a plurality of modifications in their structure. Research conducted on cell cultures subjected to 24 hours of exposure to CsA has shown that the fibers of the cytokeratin filaments are characterized by thickening and weakening adhesion to the cell membrane. ${ }^{56}$ Klawitter et $\mathrm{al}^{57}$ found that immunosuppressive drugs may increase the tissue concentration of selected cytoskeletal proteins. Other researchers confirm that CsA affects the organization of the cellular cytoskeleton. ${ }^{58}$ These reports may explain the increase in the expression of cytokeratin in the groups in which the treatment schemes contained CsA (III, V, VI). The results also show that Rapa causes a decrease in the expression of cytokeratin, in comparison to groups without the conversion to Rapa.
Research has shown that cytokeratin filaments are involved in the process of resistance against apoptosis. ${ }^{24,25}$ The resistance of epithelial cells to apoptosis is an important factor in the response to inflammation and is closely associated with the presence of cytokeratin filaments. As a result, it may be stated that mechanisms acting against inflammation could contribute to an increase in the expression of cytokeratins.

The smooth muscle cells (SMCs) of the prostate synthesize the regulatory and structural components of the extracellular matrix to create a microenvironment that regulates the growth and function of other cell types. ${ }^{59,60}$ Desmin is an integral part of the SMC and is necessary for maintaining both structural integrity and muscle function. ${ }^{22,23}$ It is also believed that desmin may be involved in the regulation processes of gene expression. ${ }^{61}$ Disorders in the expression of desmin may have a negative impact on processes in which this protein is involved.

The percentage of cells showing moderate and strong expression of desmin in groups with the conversion of treatment to monotherapy with Rapa was lower than in groups in which animals did not receive Rapa at all. Unfortunately, we could not find any publications on the impact of even single immunosuppressant drugs on the desmin in the prostate. Experiments on other experimental models can merely indirectly explain the decrease in the expression of desmin through the inhibition of muscle cell proliferation. Poon et $\mathrm{al}^{62}$ showed that Rapa inhibits the ability of vascular SMCs to migrate. Moreover, the inhibitory effect on the migration of SMC was maintained for up to 2 weeks after the administration of Rapa was halted. Li et $\mathrm{al}^{22}$ confirmed the antiproliferative effects of Rapa on SMCs.

Studies suggest that many patients who have undergone kidney transplantation continue to report sexual dysfunctions despite normal graft function. ${ }^{63,64}$ Many factors influence the proper function of the male reproductive systems in these individuals, including age, comorbid diseases, and the received immunosuppressive drugs as an integral part of therapy. It has been shown that, in patients who have received transplants, immunosuppressive drugs are the main cause of reduction in testosterone and of the occurrence of histopathological changes in the gonads. ${ }^{31,50,65}$ However, it is known that not only the testes but also other organs are responsible for fertility and reproductive capacity. Therefore, research into the influence of immunosuppressive drugs on other organs of the male reproductive system, including the prostate, seems to be justified. 


\section{Conclusion and perspectives}

It can be stated that, in the case of rats whose treatment was switched to monotherapy with Rapa during the study treatment, a decreased percentage of proliferating cells of both the glandular epithelium and stroma was found. The presented results provide further evidence for and justify the use of inhibitors of the mammalian target of Rapa in the treatment of patients with cancers, including men suffering from prostate cancer following kidney transplantation.

Based on these results, it may be also stated that immunosuppressive drugs in combination with Rapa, Tac, and Pred caused the smallest morphological and ultrastructural changes in rat prostate cells. Another advantage of this combination is the percentage of proliferating cells, which was similar to that in the control group. If the prostate is considered in isolation from the other organs of the body, this treatment scheme would seem to be the most beneficial for patients who do not suffer from prostate diseases. However, it must be remembered that an immunosuppressive therapy must always be tailored individually to the patient and must take into account any comorbid diseases.

Conducted experiment has also shown abnormalities in the ultrastructure of the prostate cells of the rats. The numerous distended cisterns of the Golgi apparatus and of the rough endoplasmic reticulum may explain the irregularities in the synthesis and secretion processes. The observed changes indicate the adverse effects of the immunosuppressive drugs on processes occurring on the intracellular level.

It is difficult to clearly interpret the observed changes in the expression of cytokeratin and desmin in the rat dorsolateral prostate. The changes in the expression profiles of the cytoskeleton proteins in the experimental groups may be the result of the direct adverse effects of the immunosuppressive drugs on the structure and organization of the IF proteins. Moreover, a number of defense mechanisms against inflammation could be activated in the cells, which, in result, could contribute to an increase in the expression of cytokeratins. The increase in the expression of these proteins may also indicate an increase in cell resistance to the apoptosis process.

Hopefully, our results not only contribute to the deeper understanding of the processes occurring in the prostate in patients undergoing immunosuppressive therapy but will also help in the individual selection of the most favorable treatment regimens that best minimize the future risk of complications, especially in men planning fatherhood.

\section{Acknowledgments}

This work was supported by the fund of Pomeranian Medical University in Szczecin for the young scientists, no MB-322$96 / 13$, and the funds were allocated for the maintenance of the research potential.

\section{Disclosure}

The authors report no conflicts of interest in this work.

\section{References}

1. Cruzado JM, Bestard O, Grinyó JM. New immunosuppressive protocols with the advent of novel biological drugs. Transplantation. 2009; 88(3 suppl):S20-S23.

2. Gummert JF, Ikonen T, Morris RE. Newer immunosuppressive drugs: a review. J Am Soc Nephrol. 1999;10(6):1366-1380.

3. Nankivell BJ, Alexander SI. Rejection of the kidney allograft. $N$ Engl J Med. 2010;363(15):1451-1462.

4. Mahmud N, Klipa D, Ahsan N. Antibody immunosuppressive therapy in solid-organ transplant. MAbs. 2010;2(2):148-156.

5. Thomson AW, Forrester JV. Therapeutic advances in immunosuppression. Clin Exp Immunol. 1994;98(3):351-357.

6. Liu YY, Li CP, Huai MS, et al. Comprehensive comparison of three different immunosuppressive regimens for liver transplant patients with hepatocellular carcinoma: steroid-free immunosuppression, induction immunosuppression and standard immunosuppression. PLoS One. 2015;10(3):e0120939.

7. Cherikh WS, Myron KH, Maghirang J, Bleyer AJ, Johnson CP. A comparison of discharge immunosuppressive drug regimens in primary cadaveric kidney transplantation. Transplantation. 2003;76(3):463-470.

8. Knoop C, Haverich A, Fischer S. Immunosuppressive therapy after human lung transplantation. Eur Respir J. 2004;23(1):159-171.

9. Ogawa T, Tokuda M, Tomizawa K, et al. Osteoblastic differentiation is enhanced by rapamycin in rat osteoblast-like osteosarcoma (ROS 17/2.8) cells. Biochem Biophys Res Commun. 1998;249(1):226-230.

10. Westrhenen R, Aten J, Hajji N, et al. Cyclosporin A induces peritoneal fibrosis and angiogenesis during chronic peritoneal exposure to a glucose-based, lactate-buffered dialysis solution in the rat. Blood Purif. 2007;25(5-6):466-472.

11. Xiao Z, Li C, Shan J, et al. Mechanisms of renal cell apoptosis induced by cyclosporine A: a systematic review of in vitro studies. Am J Nephrol. 2011;33(6):558-566.

12. Marinari R, Fleischmajer R, Schragger AH, Rosenthal AL. Mycophenolic acid in the treatment of psoriasis: long-term administration. Arch Dermatol. 1977;113(7):930-932.

13. Kleinclauss F, Gigante M, Neuzillet Y, et al. Prostate cancer in renal transplant recipients. Nephrol Dial Transplant. 2008;23:2374-2380.

14. Vasudev B, Hariharan S. Cancer after renal transplantation. Curr Opin Nephrol Hypertens. 2007;16(6):523-528.

15. Harriss DR, Savill J. Apoptosis and the prostate. Br J Urol. 1995;75(1): 27-33.

16. Nemoto R, Kawamura H, Miyakawa I, et al. Immunohistochemical detection of proliferating cell nuclear antigen (PCNA)/cyclin in human prostate adenocarcinoma. J Urol. 1993;149(1):165-169.

17. McNeal JE, Haillot O, Yemoto C. Cell proliferation in dysplasia of the prostate: analysis by PCNA immunostaining. Prostate. 1995;27(5): 258-268.

18. Bierhoff E, Vogel J, Benz M, Giefer T, Wernert N, Pfeifer U. Stromal nodules in benign prostatic hyperplasia. Eur Urol. 1996;29(3): 345-354.

19. Zhong W, Peng J, He H, et al. Ki-67 and PCNA expression in prostate cancer and benign prostatic hyperplasia. Clin Invest Med. 2008;31(1): E8-E15. 
20. Fuchs E, Weber K. Intermediate filaments: structure, dynamics, function and disease. Annu Rev Biochem. 1994;63:345-382.

21. Magin TM, Vijayaraj P, Leube RE. Structural and regulatory functions of keratins. Exp Cell Res. 2007;313(10):2021-2032.

22. Li W, Li Q, Qin L, et al. Rapamycin inhibits smooth muscle cell proliferation and obstructive arteriopathy attributable to elastin deficiency. Arterioscler Thromb Vasc Biol. 2013;33(5):1028-1035.

23. Paulin D, Li Z. Desmin: a major intermediate filament protein essential for the structural integrity and function of muscle. Exp Cell Res. 2004; 301(1): $1-7$

24. Caulin C, Ware CF, Magin TM, Oshima RG. Keratin-dependent, epithelial resistance to tumor necrosis factor-induced apoptosis. $J$ Cell Biol. 2000;149(1):17-22.

25. Inada $\mathrm{H}$, Izawa I, Nishizawa $\mathrm{M}$, et al. Keratin attenuates tumor necrosis factor-induced cytotoxicity through association with TRADD. J Cell Biol. 2001;155(3):415-426.

26. Ayala G, Tuxhorn JA, Wheeler TM, et al. Reactive stroma as a predictor of biochemical-free recurrence in prostate cancer. Clin Cancer Res. 2003;9(13):4792-4801.

27. Okada H, Tsubura A, Okamura A, et al. Morii S: keratin profiles in normal/hyperplastic prostates and prostate carcinoma. Virchows Arch A Pathol Anat Histopathol. 1992;421(2):157-161.

28. Van Leenders GJ, Aalders TW, Hulsbergen-van de Kaa CA, Ruiter DJ, Schalken JA. Expression of basal cell keratins in human prostate cancer metastases and cell lines. J Pathol. 2001;195(5):563-570.

29. Abou-Ismail UA, Mahboub HD. The effects of enriching laboratory cages using various physical structures on multiple measures of welfare in singly-housed rats. Lab Anim. 2011;45(3):145-153.

30. Spangenberg EM, Augustsson H, Dahlborn K, Essén-Gustavsson B, Cvek K. Housing-related activity in rats: effects on body weight, urinary corticosterone levels, muscle properties and performance. Lab Anim. 2005;39(1):45-57.

31. Chen Y, Zhang Z, Lin Y, et al. Long-term impact of immunosuppressants at therapeutic doses on male reproductive system in unilateral nephrectomized rats: a comparative study. Biomed Res Int. 2013; 2013:690382

32. Masuda H, Fujihira S, Ueno H, Kagawa M, Katsuoka Y, Mori H. Ultrastructural study on cytotoxic effects of cyclosporine A in spermiogenesis in rats. Med Electron Microsc. 2003;36(3):183-191.

33. Seethalakshmi L, Diamond DA, Malhotra RK, Mazanitis SG, Kumar S, Menon M. Cyclosporine-induced testicular dysfunction: a separation of the nephrotoxic component and an assessment of a 60-day recovery period. Transplant Proc. 1988;20(3):1005-1010.

34. Srinivas M, Agarwala S, Datta Gupta S, et al. Effect of cyclosporine on fertility in male rats. Pediatr Surg Int. 1998;13(5-6):388-391.

35. Freitas KM, Monteiro JC, Gomes ML, Taboga SR, Dolder H. Cyclosporin A causes impairment of the ventral prostate tissue structure of Wistar rats. Hum Exp Toxicol. 2012;31(12):1262-1270.

36. Freitas KM, Monteiro JC, Gomes ML, Taboga SR, Dolder H. Heteropterys tomentosa (A. Juss.) infusion counteracts Cyclosporin a side effects on the ventral prostate. BMC Complement Altern Med.2013; 13(30):30-39.

37. Grabowska M, Słuczanowska-Głąbowska S, Kram A, et al. The influence of immunosuppressants on the morphology, proliferating cell nuclear antigen (PCNA) and apoptosis in the rat ventral prostate. Histol Histopathol. 2015;30(9):1089-1100.

38. Jolicoeur EM, Qi S, Xu D, Dumont L, Daloze P, Chen H. Combination therapy of mycophenolate mofetil an rapamycin in prevention of chronic renal allograft rejection in the rat. Transplantation. 2003;75(1): $54-59$.

39. Katz IA, Takizawa M, Jaffe II, Stein B, Fallon MD, Epstein S. Comparision of the effects of FK506 and cyclosporine on bone mineral metabolism in the rat. A pilot study. Transplantation. 1991;52(3):571-574.

40. Aumüller G, Enderle-Schmitt U, Seitz J, Muntzing J, Chandler JA. Ultrastructure and immunohistochemistry of the lateral prostate in aged rats. Prostate. 1987;10(3):245-256.
41. Sikorski A. Comparative light microscopic study of the lobes of the rat prostate. Folia Morphol. 1981;40(1):63-72.

42. Bancroft JD, Gamble M. Standard hematoxylin and eosin stain for paraffin sections. In: Bancroft JD, Gamble M, editors. Theory and Practice of Histological Techniques. London: Churchill Livingstone; 2002:135-136.

43. Grabowska M, Słuczanowska-Głąbowska S, Rył A, Piasecka M, Laszczyńska M. The impact of selected immunosuppressive drugs: rapamycin, cyclosporine $\mathrm{A}$ and prednisone on immunolocalization and immunoexpression of cytokeration in prostate gland - experimental model. J Public Health Nurs Med Rescue. 2014;4:77-82.

44. Romijn HJ, Hofman MA, Gramsbergen A. At what age is the developing cerebral cortex of the rat comparable to that of the full-term newborn human baby? Early Hum Dev. 1991;26(1):61-67.

45. Quinn R. Comparing rat's to human's age: how old is my rat in people years? Nutrition. 2005;21(6):775-777.

46. Munivenkatappa R, Haririan A, Papadimitriou JC, Drachenberg CB, Dinits-Pensy M, Klassen DK. Tubular epithelial cell and podocyte apoptosis with de novo sirolimus based immunosuppression in renal allograft recipients with DGF. Histol Histopathol. 2010;25(2):189-196.

47. Caneguim BH, Cerri PS, Spolidório LC, Miraglia SM, Sasso-Cerri E. Structural alterations in the seminiferous tubules of rats treated with immunosuppressor tacrolimus. Reprod Biol Endocrinol. 2009;7:19.

48. Damoiseaux JG, Defresne MP, Reutelingsperger CP, Van Breda Vriesman PJ. Cyclosporin-A differentially affects apoptosis during in vivo rat thymocyte maturation. Scand J Immunol. 2002;56(4): 353-360.

49. Ysebaert DK, De Greef KE, Vercauteren SR, et al. Effect of immunosuppression on damage, leukocyte infiltration, and regeneration after severe warm ischemia/reperfusion renal injury. Kidney Int. 2003; 64(3):864-873.

50. He Z, Qiu J, Li J, Zhao D, Chen G, Chen L. Long-term effects of conversion from cyclosporine to rapamycin on testicular function and morphology in a rat transplantation model. Transplant Proc. 2013;45(2): 763-769.

51. Rovira J, Diekmann F, Ramírez-Bajo MJ, Bañón-Maneus E, Moya-Rull D, Campistol JM. Sirolimus-associated testicular toxicity: detrimental but reversible. Transplantation. 2012;93(9):874-879.

52. Rovira J, Marcelo AE, Burke JT, et al. Effect of mTOR inhibitor on body weight: from an experimental rat model to human transplant patients. Transpl Int. 2008;21(10):992-998.

53. Zhuang QY, Chen XG, Dong ZQ, Liu JH, Ye ZQ. Effects of rapamycin on prostate cancer PC-3 cells. Ai Zheng. 2009;28(8):851-855.

54. Javier AF, Bata-Csorgo Z, Ellis CN, Kang S, Voorhees JJ, Cooper KD. Rapamycin (sirolimus) inhibits proliferating cell nuclear antigen expression and blocks cell cycle in the G1 phase in human keratinocyte stem cells. J Clin Invest. 1997;99(9):2094-2099.

55. Steinert P. Intermediate filaments in health and disease. Exp Mol Med. 1996;28:55-63.

56. Vernetti LA, Gandolfi AJ, Nagle RB. Selective alteration of cytokeratin intermediate filament by cyclosporine A is a lethal toxicity in PTK2 cell cultures. Adv Exp Med Biol. 1991;283:847-851.

57. Klawitter J, Klawitter J, Kushner E, et al. Association of immunosuppressant-induced protein changes in the rat kidney with changes in urine metabolite patterns: a proteo-metabonomic study. J Proteome Res. 2010;9(2):865-875.

58. Prignano F, Domenici-Lombardo L, Gerlini G, Pimpinelli N, Romagnoli P. Cyclosporin-A affects the organization of cytoskeleton of normal human keratinocytes in culture. Histol Histopathol. 1996;11(4): 889-894.

59. Antonioli E, Della-Colleta HH, Carvalho HF. Smooth muscle cell behavior in the ventral prostate of castrated rats. J Androl. 2004;25(1): $50-56$.

60. Thomson AA, Timms BG, Barton L, Cunha GR, Grace OC. The role of smooth muscle in regulating prostatic induction. Development. 2002;129(8):1905-1912. 
61. Costa ML, Escaleira R, Cataldo A, Oliveira F, Mermelstein CS. Desmin: molecular interactions and putative functions of the muscle intermediate filament protein. Braz J Med Biol Res. 2004;37(12):1819-1830.

62. Poon M, Marx SO, Gallo R, Badimon JJ, Taubman MB, Marks AR. Rapamycin inhibits vascular smooth muscle cell migration. JClin Invest. 1996;98(10):2277-2283.

63. Hricik DE, Halbert RJ, Barr ML, et al. Life satisfaction in renal transplant recipients: preliminary results from the transplant learning center. Am J Kidney Dis. 2001;38(3):580-587.
64. Malavaud B, Rostaing L, Rischmann P, Sarramon JP, Durand D. High prevalence of erectile dysfunction after renal transplantation. Transplantation. 2000;69(10):2121-2124.

65. Bererhi L, Flamant M, Martinez F, Karras A, Thervet E, Legendre C. Rapamycin-induced oligospermia. Transplantation. 2003;76(5): 885-886. 


\section{Supplementary materials}

Table SI Percentage of PCNA-positive epithelial and stromal cells in the rat dorsolateral prostate in control (I) and experimental (II-VIII) groups

\begin{tabular}{|c|c|c|c|c|c|c|c|}
\hline \multirow[t]{2}{*}{ Group } & \multirow[t]{2}{*}{ Given drugs } & \multicolumn{3}{|c|}{ PCNA-positive cells in epithelium (\%) } & \multicolumn{3}{|c|}{ PCNA-positive cells in stroma (\%) } \\
\hline & & Min-max & Me & $\bar{x} \pm$ SD & Min-max & Me & $\bar{x} \pm \mathbf{S D}$ \\
\hline I & - & $12.7-30.4$ & 22.3 & $22.3 \pm 4.1$ & $6.5-25.0$ & 15.6 & $16.0 \pm 3.6$ \\
\hline II & Rapa, Tac, Pred & $|5.2-3| .6$ & 22.4 & $22.5 \pm 4.0$ & $10.0-25.4$ & 16.9 & $16.6 \pm 3.8$ \\
\hline III & Rapa, CsA, Pred & $17.7-36.7$ & 30.0 & $29.3 * \pm 4.6$ & $12.5-28.4$ & 18.0 & $18.6 * \pm 3.9$ \\
\hline IV & Rapa, MMF, Pred & $23.5-36.0$ & 30.8 & $30.0 * \pm 3.3$ & II.8-24.3 & 18.3 & $18.3 \pm 3.6$ \\
\hline $\mathrm{V}$ & CsA, MMF, Pred & $|7.2-3| .0$ & 22.5 & $22.9 \pm 3.3$ & $9.6-25.0$ & 15.8 & $17.2 \pm 4.5$ \\
\hline $\mathrm{VI}$ & CsA, MMF, Pred/Rapa & $|0.1-3| .3$ & 15.7 & $16.0^{\mathrm{a}, * \pm 4.2}$ & $9.0-25.0$ & 14.8 & $14.8^{\mathrm{a}} \pm 3.6$ \\
\hline VII & Tac, MMF, Pred & $16.1-34.8$ & 23.7 & $24.3 \pm 4.8$ & $10.9-23.6$ & 16.6 & $16.4 \pm 2.9$ \\
\hline VIII & Tac, MMF, Pred/Rapa & $8.6-23.3$ & 15.8 & $16.6^{\mathrm{a}, * \pm 3.2}$ & $3.8-17.4$ & 12.1 & $1 I . I^{\mathrm{a}, *} \pm 3.7$ \\
\hline
\end{tabular}

Notes: $* P<0.05$ vs control. aGroups with the conversion of the treatment to Rapa, significantly different $(P<0.05)$ vs the groups without Rapa (VI vs $V$ and $\mathrm{VIII}$ vs $\mathrm{VII})$. Abbreviations: CsA, cyclosporin A; Me, median; Min-max, minimum-maximum values; MMF, mycophenolate mofetil; Rapa, rapamycin; PCNA, proliferating cell nuclear antigen; Pred, prednisone; Tac, tacrolimus; $\bar{x} \pm \mathrm{SD}$, mean \pm standard deviation.

Table S2 Percentage of cytokeratin-positive cells in the rat dorsolateral prostate in control (I) and experimental (II-VIII) groups

\begin{tabular}{|c|c|c|c|c|c|c|c|c|c|c|}
\hline \multirow[t]{2}{*}{ Group } & \multirow[t]{2}{*}{ Given drugs } & \multicolumn{3}{|c|}{$\begin{array}{l}\text { Cells with weak expression of } \\
\text { cytokeratin (\%) }\end{array}$} & \multicolumn{3}{|c|}{$\begin{array}{l}\text { Cells with moderate } \\
\text { expression of cytokeratin (\%) }\end{array}$} & \multicolumn{3}{|c|}{$\begin{array}{l}\text { Cells with strong expression } \\
\text { of cytokeratin (\%) }\end{array}$} \\
\hline & & Min-max & Me & $\bar{x} \pm$ SD & Min-max & Me & $\bar{x} \pm \mathbf{S D}$ & Min-max & Me & $\bar{x} \pm \mathbf{S D}$ \\
\hline I & - & $36.1-71.0$ & 58.8 & $58.4 \pm 7.3$ & $1.0-30.7$ & 13.2 & $14.4 \pm 8.5$ & $0.1-7.7$ & 0.6 & $1.6 \pm 1.8$ \\
\hline II & Rapa, Tac, Pred & $16.0-50.7$ & 41.8 & $39.5 * \pm 8.3$ & $16.6-53.9$ & 37.9 & $36.2 * \pm 9.7$ & $6.5-38.0$ & 14.4 & $16.0 * \pm 7.0$ \\
\hline III & Rapa, CsA, Pred & $19.4-49.7$ & 30.7 & $32.2 * \pm 7.5$ & $26.3-57.2$ & 43.9 & $43.0 * \pm 6.9$ & $4.3-42.3$ & 22.3 & $21.0 * \pm 9.8$ \\
\hline IV & Rapa, MMF, Pred & $10.0-39.2$ & 23.9 & $24.7 * \pm 7.3$ & $20.7-56.5$ & 46.6 & $44.2 * \pm 8.0$ & $9.3-44.8$ & 25.3 & $26.1 * \pm 9.6$ \\
\hline v & CsA, MMF, Pred & $10.4-45.6$ & 28.9 & $28.2 * \pm 7.6$ & $34.9-55.0$ & 45.2 & $44.2 * \pm 5.5$ & $9.6-47.1$ & 23.2 & $24.5^{*} \pm 8.8$ \\
\hline VI & CsA, MMF, Pred/Rapa & 18.3-54.4 & 31.2 & $30.5 * \pm 8.3$ & $|0.1-5| .2$ & 40.8 & $38.8 * \pm 9.0$ & $1.5-39.7$ & 22.9 & $22.9 * \pm 9.6$ \\
\hline VII & Tac, MMF, Pred & $4.1-34.3$ & 16.3 & $17.6 * \pm 6.7$ & $21.8-50.1$ & 38.1 & $37.3 * \pm 7.4$ & $21.2-61.8$ & 43.7 & $44.0 * \pm 9.6$ \\
\hline VIII & Tac, MMF, Pred/Rapa & II.2-45.3 & 28.7 & $27.8^{\mathrm{a}, * \pm 8.9}$ & $18.4-50.7$ & 33.0 & $34.8^{*} \pm 7.7$ & $14.6-46.6$ & 30.4 & $30.4^{\mathrm{a}, * \pm 9.8}$ \\
\hline
\end{tabular}

Notes: $* P<0.05$ vs control. a Groups with the conversion of the treatment to Rapa, significantly different $(P<0.05)$ vs the groups without Rapa (VI vs $V$ and $V I I I$ vs $V I I)$. Abbreviations: CsA, cyclosporin A; Me, median; Min-max, minimum-maximum values; MMF, mycophenolate mofetil; Pred, prednisone; Rapa, rapamycin; Tac, tacrolimus; $\bar{x} \pm \mathrm{SD}$, mean \pm standard deviation.

Table S3 Percentage of desmin-positive cells in the rat dorsolateral prostate in control (I) and experimental (II-VIII) groups

\begin{tabular}{|c|c|c|c|c|c|c|c|c|c|c|}
\hline \multirow[t]{2}{*}{$\overline{\text { Group }}$} & \multirow[t]{2}{*}{ Given drugs } & \multicolumn{3}{|c|}{$\begin{array}{l}\text { Cells with weak expression of } \\
\text { desmin (\%) }\end{array}$} & \multicolumn{3}{|c|}{$\begin{array}{l}\text { Cells with moderate } \\
\text { expression of desmin (\%) }\end{array}$} & \multicolumn{3}{|c|}{$\begin{array}{l}\text { Cells with strong expression } \\
\text { of desmin (\%) }\end{array}$} \\
\hline & & Min-max & Me & $\bar{x} \pm$ SD & Min-max & $\mathrm{Me}$ & $\bar{x} \pm$ SD & Min-max & Me & $\bar{x} \pm \mathbf{S D}$ \\
\hline I & - & $29.2-60.7$ & 51.5 & $50.3 \pm 7.7$ & $17.5-48.3$ & 31.3 & $31.1 \pm 6.7$ & $0.9-22.9$ & 4.4 & $5.9 \pm 4.9$ \\
\hline II & Rapa, Tac, Pred & $7.6-47.0$ & 22.9 & $22.8^{*} \pm 6.8$ & $17.4-39.4$ & 26.9 & $27.0 \pm 5.5$ & $16.8-69.0$ & 44.2 & $45.7 * \pm 10.3$ \\
\hline III & Rapa, CsA, Pred & $32.4-69.9$ & 47.8 & $48.9 \pm 9.1$ & $7.4-33.0$ & 17.2 & $17.9 * \pm 5.2$ & $0.2-10.1$ & 1.9 & $2.4 \pm 2.0$ \\
\hline IV & Rapa, MMF, Pred & $36.6-69.9$ & 52.1 & $52.2 \pm 7.7$ & $1.2-23.0$ & 11.3 & $11.9 * \pm 4.5$ & $0.1-6.6$ & I.I & $1.5^{*} \pm \mathrm{I} .4$ \\
\hline V & CsA, MMF, Pred & II.I-42.3 & 28.5 & $27.3^{*} \pm 7.9$ & $25.6-56.1$ & 41.0 & $41.2 * \pm 6.8$ & $11.6-43.8$ & 27.7 & $27.8^{*} \pm 7.8$ \\
\hline VI & CsA, MMF, Pred/Rapa & $36.4-67.1$ & 52.1 & $52.2^{\mathrm{a}} \pm 6.4$ & $13.8-43.2$ & 33.3 & $32.9^{a} \pm 6.3$ & $0.6-18.7$ & 6.7 & $7.2^{\mathrm{a}} \pm 3.7$ \\
\hline VII & Tac, MMF, Pred & $15.0-39.6$ & 26.1 & $26.4^{*} \pm 6.7$ & $34.1-58.1$ & 48.7 & $47.4^{*} \pm 5.9$ & $9.2-36.2$ & 22.7 & $23.3^{*} \pm 7.0$ \\
\hline VIII & Tac, MMF, Pred/Rapa & |4.7-55.| & 30.5 & $32.6 * \pm 11.8$ & $20.4-58.0$ & 36.7 & $38.8^{\mathrm{a}, * \pm 9.6}$ & $5.4-37.6$ & 21.9 & $22.6 * \pm 9.2$ \\
\hline
\end{tabular}

Notes: $* P<0.05$ vs control. a Groups with the conversion of the treatment to Rapa, significantly different $(P<0.05)$ vs the groups without Rapa (VI vs $V$ and $\mathrm{VIII}$ vs VII). Abbreviations: CsA, cyclosporin A; Me, median; Min-max, minimum-maximum values; MMF, mycophenolate mofetil; Rapa, rapamycin; Pred, prednisone; Tac, tacrolimus; $\bar{x} \pm \mathrm{SD}$, mean \pm standard deviation. 


\section{Publish your work in this journal}

Drug Design, Development and Therapy is an international, peerreviewed open-access journal that spans the spectrum of drug design and development through to clinical applications. Clinical outcomes, patient safety, and programs for the development and effective, safe, and sustained use of medicines are the features of the journal, which has also been accepted for indexing on PubMed Central. The manuscript management system is completely online and includes a very quick and fair peer-review system, which is all easy to use. Visit http://www.dovepress.com/testimonials.php to read real quotes from published authors.

Submit your manuscript here: http://www.dovepress.com/drug-design-development-and-therapy-journal 